\title{
“Os ogros são como cebolas”: diferentes ofertas de subjetivação presentes na personagem Shrek
}

\section{“Ogres are like onions": different subjectivations present in the Shrek character}

Myrna Wolff Brachmann dos Santos i

Antônio Carlos do Nascimento Osório ii

\begin{abstract}
i Pedagogia - FaEd - Faculdade de Educação, Universidade Federal de Mato Grosso do Sul, Campo Grande, MS, Brasil.myrna.wb.santos@ufms.br

ii Pedagogia - FaEd - Faculdade de Educação, Universidade Federal de Mato Grosso do Sul, Campo Grande, MS, Brasil. antonio.osorio@ufms.br.
\end{abstract}

\begin{abstract}
Resumo
Este texto constitui breve exposição de análise dos quatro filmes de animação da série Shrek - Shrek (2001), Shrek 2 (2004), Shrek Terceiro (2007), Shrek para Sempre (2010) - realizada com o objetivo de descrever e refletir sobre os processos de subjetivação que produzem a personagem Shrek. Pressupõe que os filmes, em sua capacidade pedagógica, oferecem e propõem alternativas de subjetivação, além de modelos e exemplos de modos de ser, pensar e agir. Apresenta a ideia de que a personagem do ogro sofre um processo de subjetivação, que o torna mais ou menos normalizado. Ao sujeito espectador, infante (ou não), os filmes da série Shrek oferecem uma ideia de humanização e de conformação às normas que regem socialmente o uso da sexualidade. Os processos que tornam a personagem Shrek normalizada, bem como, e de certa forma, humanizada, são tratados como ofertas exemplares e modelares de como cuidar de si.
\end{abstract}

Palavras-chave: subjetivação, cuidado de si, constituição de si 


\title{
pro.posıções
}

\begin{abstract}
This text is brief explanatory analysis of four animated films in the series Shrek - Shrek (2001), Shrek 2 (2004), Shrek the third (2007), Shrek forever after (2010) - in order to describe and reflect on the processes of subjectivation that produce the Shrek character. The assumption is that the films in their educational capacity, offer and propose alternative subjectivation in addition to models and examples of ways of being, thinking and acting. It presents the idea that the ogre character undergoes a process of subjectivation, which makes it more or less standardised. To the subject viewer, child (or not), the Shrek series films offer an idea of bumanization and conformation to the rules governing the use of sexuality socially. The processes that make the Shrek character normalized as well, and in some ways, bumanized, are treated as exemplary and offer models of how to care of self.
\end{abstract}

Keywords: subjectivation, care of self, constitution of self

Shrek foi um sucesso de bilheteria no cinema, faturou muito com a vendagem de produtos forjados a partir dos seus personagens, originou, além dos filmes, jogos para videogame e desenhos para a TV. Alcançou cifras gigantescas para a DreamWorks SKG (Denis, 2010) ${ }^{1}$. Desenhos e filmes continuam sendo exibidos na TV brasileira, aberta e por assinatura, com alguma frequência. Que mecanismos fizeram ser tão bem aceitas (e lucrativas!) a figura e a história do ogro Shrek? Temos algo de Shrek em nós?

Este estudo se limita a apontar os aspectos apresentados nos filmes como exemplares, e a analisá-los a partir das técnicas de endereçamento de que eles lançam mão. Foram analisados os quatro filmes de animação da série Shrek - Shrek (2001), Shrek 2

\footnotetext{
${ }^{1}$ Digitando "Shrek" em um site de busca da web, o Google (www.google.com.br), obtém-se um número aproximado de 27.000 .000 resultados. Diferentes sites também mencionam o enorme faturamento que os filmes e os demais produtos criados a partir da série Shrek alcançaram nas vendagens (pesquisas realizadas em 25 de setembro de 2015).
} 


\section{pro.posições}

(2004), Shrek Terceiro (2007), Shrek para Sempre (2010)². Foi tarefa da pesquisa analisar os processos de subjetivação de Shrek pelos quais ele se constitui e, a partir disso, refletir sobre o modo como eles se apresentam como modelos/exemplos para os espectadores. Nesse sentido é que caminhamos em direção a um pensar sobre como também nós somos subjetivados em meio às relações e às experiências que vivenciamos.

Destarte, frisamos a capacidade do cinema e dos filmes, como possibilidade de serem tomados como pedagógicos naquilo que veiculam. Com isso, estamos querendo dizer que os filmes "ensinam coisas" ao oferecer modelos/ideias. São "pedagógicos" na medida em que exibem modelos, exemplos em torno de normas estipuladas socialmente e que podem ser tomadas como mediadoras das experiências dos espectadores.

Utilizar os filmes como material de análise determina uma delimitação maior do que a pesquisa que investiga o cinema (Duarte, 2006). Permite lidar com os filmes de modo variado, desenvolver possibilidades de leituras "fracionando-se suas diferentes estruturas de significação e reorganizando-as novamente segundo critérios previamente estabelecidos, de acordo com objetivos que se quer atingir" (pp.98-99).

Para analisar o material assistimos muitas vezes aos filmes, anotando, reprisando, procurando descrever os diálogos, as cenas, dentre outros aspectos que fomos considerando significativos para as temáticas a serem estudadas. Tais elementos foram analisados, segundo alguns conceitos de Foucault.

O estudo considerou, portanto, os quatro filmes da série Shrek, dos quais selecionamos aquilo que julgamos vinculável à temática, para construir uma análise que pudesse refletir sobre as ofertas de subjetivação da personagem apresentadas como modelo, e sobre os mecanismos utilizados para normalizar uma figura considerada monstruosa (o ogro).

\footnotetext{
2 Os filmes da série Shrek, de criação computadorizada, foram produzidos pela DreamWorks SKG, como cinema de animação, recurso que combina uma variedade de técnicas e que permite a elaboração de filmes de diferentes gêneros. Podem-se encontrar mais informações sobre a DreamWorks SKG ou sobre o cinema de animação na obra de Denis (2010).
} 


\section{pro.posıçõoses}

\section{Os filmes e sua presença na vida cotidiana}

Os filmes (de todos os gêneros e classificações etárias) estão cada vez mais presentes no cotidiano das crianças e fazem parte de um conjunto maior de elementos culturais que corroboram os processos de subjetivação dos sujeitos. Nisso entendemos residir a importância de empreender análises de filmes no âmbito da pesquisa em educação.

A existência do direcionamento de alguns filmes para o público infantil torna-se um aspecto relevante de ser tomado em consideração. Outro aspecto importante é o frequente contato com uma diversidade de recursos midiáticos, tecnológicos, que muitas crianças, de diferentes idades, têm experimentado, o que tem permitido que o cinema, sobretudo o cinema indústria ${ }^{3}$, esteja presente em vários espaços de vivência das crianças, entre eles, o espaço escolar.

Podemos dizer que os filmes, especialmente os do cinema dominante, são consumidos e estão presentes em grande quantidade nas famílias e nas escolas, e atualmente, inclusive, nas famílias com menores condições financeiras (Duarte \& Alegria, 2008; Momo, 2009). Os filmes são, por diversas vezes, usados para divertir as crianças e, noutras, para ocupá-las por algum tempo (Costa, 2002).

As crianças têm contato com certa diversidade de filmes já a partir da tenra idade. Eles estão presentes na escola, nos centros de educação infantil, nas residências, participando da produção do imaginário infantil. São recorrentes nas brincadeiras, nos produtos direcionados para os infantes (materiais escolares, brinquedos, roupas), nos jogos de videogame, nas decorações de ambientes diversos e em uma multiplicidade de situações e objetos voltados para a infância. Têm sido companhia e fomento aos jogos que oscilam entre a imaginação e a realidade na vivência das crianças, e vão introduzindo, aos poucos, as crianças e os adolescentes no hábito contemporâneo de assistir a filmes. Eles estão também presentes no espaço escolar, para que o professor, pelos mais diferentes motivos, lance mão dessa possibilidade sempre que necessitar ou achar conveniente (Mayrink, 2007; R. Silva, 2007; Vieira, 2008).

\footnotetext{
3 Cinema indústria, também chamado cinema dominante, cinema para as massas, cinema popular, cinema comercial, ou às vezes simplesmente, cinema hollywoodiano, são expressões que designam as produções cinematográficas produzidas com objetivo lucrativo, preponderantemente comercial e que acabam por criar mundialmente um padrão de gosto e preferência, conforme Duarte (2006).
} 


\section{pro.posições}

Costa (2002) comenta que o "currículo da mídia" não se define impositivamente. Ele conquista a adesão dos espectadores pelo fascínio que exerce com o uso de cores, imagens e brilho combinados para atrair a atenção: "Chega-se a ele por interesse e deleite, e, pelo mesmo motivo, adere-se a ele. Ao longo de nossas vidas, ... ele é responsável por uma boa parcela de aprendizados sobre o mundo, sobre os outros e sobre nós mesmos" (p. 80). Nessa construção de subjetividades, as crianças são alvos preferenciais.

É preciso destacar que há diferenças nas experiências de assistir a filmes no cinema, na escola ou no espaço das residências e, portanto, diferenças na forma de problematizar as ofertas de subjetivação em cada caso. Mas nossa atenção volta-se para os filmes como objeto de análise, disponíveis nas mais diversas formas de acesso: outrora no cinema (no caso dos filmes da série em questão), por enquanto na TV aberta e por assinatura, em DVDs, em cópias não autorizadas, na internet, podendo ser copiados e armazenados em diferentes dispositivos móveis e que ainda podem ser projetados, pausados, reeditados. Permitem a interação das crianças com os menus que disponibilizam "bônus especiais", making of das gravações, jogos e uma infinidade de recursos.

Portanto, queremos enfatizar a relevância de investigar filmes voltados para o público infantil, dada a presença deles na vida de muitas crianças, pelo que realçamos a coparticipação desses em sua formação geral, destacando-se a capacidade e/ou a possibilidade de os filmes (e do cinema em geral) funcionarem pedagogicamente, atuando nos processos de subjetivação dos sujeitos espectadores.

Essa relação entre a possibilidade que o cinema tem de educar o sujeito e a relação dele com o espectador é exposta por Ellsworth (2001) em termos de modos de endereçamento. Segundo a autora, os produtores sempre elaboram seus filmes tendo em vista, consciente e inconscientemente, posições de sujeito. No entanto, nem sempre o filme atinge o público como esperado, o filme sempre "erra" o seu alvo, em um ou em vários sentidos.

Vários aspectos concorrem para que isso ocorra, dentre eles, o fato de que cada sujeito espectador pode relacionar-se com um modo de endereçamento, distanciando-se de outros; o fato de que cada sujeito não é aquilo que o filme pensa que ele é, ou que o sujeito não é aquilo que ele mesmo pensa que é. Assim, o sucesso de um filme dependeria muito mais dos modos de endereçamento que conseguem estabelecer alguma relação com o espectador do que apenas de uma boa história ou de uma boa atuação do elenco (Ellswoth, 


\section{pro.posiç̧ões}

2001). Nesse sentido, a popularidade de um filme indica, entre outras coisas, que diversos dos endereçamentos ali presentes alcançaram, de algum modo, os sujeitos.

Giroux (2004) chama a atenção para a necessidade de que a dimensão pedagógica dos filmes produzidos para crianças seja tomada como princípio definidor, tornando-se alvo de estudos e questionamentos “questões sobre 'como' e 'o que' as crianças aprendem [ênfase no original]" (p. 76).

Defendendo a ideia de que somos produzidos também, e fortemente, por essa cultura midiática e tecnológica, Fischer (2007), por meio de suas pesquisas, afirma:

todas essas mídias, do rádio à internet e à televisão, têm um caráter de onipresença, tornam-se cada vez mais essenciais em nossas experiências contemporâneas, e assumem características de produção, veiculação e consumo e usos específicos em cada lugar do mundo. (p. 293)

Informações, ideias, modos de existência e realidades culturais ou imaginárias chegam às crianças por meio dos filmes. Situações-problema de inúmeros tipos, imagens gravadas, produzidas em computador, ou ainda as duas coisas, exibidas ao som de uma infinidade de músicas e sons diversos, cores e efeitos, são parte das inúmeras possibilidades midiáticas e audiovisuais cada vez mais familiares às crianças.

\section{Shrek e alguns modos de compreendê-lo}

Os filmes da série Shrek são intrigantes e conquistaram a atenção de muitos ${ }^{4}$. Seus personagens, suas tramas e suas representações suscitam muitas inquietações, tais como: feiura e beleza; beleza e padrões sociais, representações de gênero, opções de sexualidade diferenciadas. Há surpresas como: um burro que fala, que se apaixona e tem filhotes com um Dragão-Fêmea; um rei-sapo; uma Fada Madrinha malvada, excêntrica, que faz dieta e tem uma solução mágica para a celulite; um anão, como presente de chá de bebê; uma

\footnotetext{
4 São também estudos que contemplam análises de filmes da série Shrek: Bilotta, 2010; Corrêa, 2006;
} Machado, 2006; Santos, 2009; Silva, E. 2007. 


\section{pro.posições}

Rapunzel careca, cujo cabelo é aplique e que é uma traidora; o Capitão Gancho tocando piano e cantando, fazendo um som ambiente em um bar. Há confusões como: o Burro falante no corpo do Gato de Botas e o Gato de Botas no corpo do Burro falante. São inusitadas também a inserção de cenas como: a queima de sutiã; o Gato pego em flagrante, portando droga (mesmo sem ser o vilão da história); a Chapeuzinho Vermelho, incluída entre os vilões do reino e achada roubando dinheiro de um senhor; o Shrek, identificandose e usando argumentos de sindicalistas para conseguir entrar na propriedade da Fada Madrinha...

Dentre essas inquietações e possibilidades de estudo e análises, escolhemos compreender a personagem de Shrek que é um ogro - algo também inesperado quando os ogros costumam ser os vilões.

Um ogro, na literatura, remete às figuras dos vilões a serviço do mal (Santos, 2009). Sua função nas histórias é a de representar as forças maléficas, demoníacas. No francês, ogre, é a figura utilizada para "intimidar as crianças", pois é um ser que devora pessoas, muitas vezes associado à figura folclórica do "papão" ou "bicho-papão".

O ogro, além de monstruoso e maléfico, designa, segundo a pesquisa de Santos (2009), o "gigante dos contos de fadas que se alimentava de carne humana, de origem controversa, provavelmente do latim Orcus, divindade infernal” (p. 68). Os ogros seriam, assim, criaturas demoníacas, danosas, incapazes de bondade, cruéis e monstruosas ao ponto de se alimentarem de humanos ${ }^{5}$.

Inicialmente, é a essa figura monstruosa que a personagem alude. Necessário destacar, aqui, que a personagem Shrek não se apresenta como uma pessoa, um sujeito, que possa ser subjetivado. Ele é uma personagem de ficção, encarnada na figura animada de um ogro $^{6}$, cuja apresentação constitui um modo deliberado por seus criadores. Tal personagem, existindo como um ogro, o distancia ainda mais da realidade, por ser essa figura monstruosa dos contos de fadas. No entanto, quisemos dar vulto ao modo como os

\footnotetext{
${ }^{5}$ Há menções de que, em 1697, Charles Perrault (1628-1703) tenha narrado a história do Pequeno Polegar e nela havia como personagem um ogro que aterrorizava as crianças. Gustave Doré (1832-1883) teria ilustrado essa personagem (dentre outras imagens criadas para ilustrar contos e fábulas infantis). Retirado em 10 de dezembro de 2015, de <http://pt.wikipedia.org/wiki/Gustave_Dor\%C3\%A9>; $<$ https://pt.wikipedia.org/wiki/Charles_Perrault>.

${ }^{6}$ Gomes (2011) nos esclarece que uma personagem cinematográfica é sempre fictícia e só começa a existir quando encarnada em uma pessoa, um ator. Nesse caso, a personagem de Shrek existe na figura animada que vemos atuando no filme.
} 


\section{pro.posições}

idealizadores-produtores, que criaram a personagem para o cinema, puderam fabricá-lo, conforme uma dada ideia de humanidade. Nesse sentido é que buscamos analisar os mecanismos que vão transformando Shrek, um ogro, em uma figura normalizada e, de certa forma, humanizada. Há muitas outras formas possíveis para se compreender Shrek (ou os demais personagens da série). Esta é apenas uma.

Mas quem é Shrek, afinal? ${ }^{7}$ Como ele é subjetivado? Shrek é, primeiramente, uma personagem de sucesso do cinema - dessas que alcançou cifras gigantescas para a SKG (Denis, 2010). É na medida em que seu sucesso comercial, sua capacidade de agradar adultos e crianças se tornam abrangentes que ele nos interessa, visto que sua história, seus modos de ser, pensar e agir chegam a muitos sujeitos e se oferecem a eles como uma possibilidade de constituição de si mesmo. Sua existência como personagem fictícia, irreal, nos obriga a tomá-la inteiramente nessa sua condição imaginária.

Os espectadores (crianças ou não) aprendem coisas com os filmes, conscientes ou não desse processo. Os filmes podem atuar circunscrevendo, mediando, intervindo, sugerindo, propondo, fixando formas diferenciadas de constituição de si, de experiências consigo mesmo - formas de subjetivação. Sua capacidade é adensada, tanto por constituir uma riqueza tecnológica quanto por lidar com emoção, razão, desrazão, sonhos, fantasias, desejos, angústias e outros sentimentos e emoções dos espectadores.

Ao falarmos em subjetivação, estamos fazendo referência a um conceito de Foucault $(1988,2004)$ que busca significar os modos como o sujeito se relaciona consigo mesmo e opera sobre si, constituindo-se, modificando-se. Tais operações sempre se dão nos processos de construções possíveis na relação com a verdade, com o saber, com o poder, na relação com o outro e, por fim, na relação consigo mesmo. Em outras palavras, a relação do sujeito consigo mesmo é contingenciada, mais - ou menos - determinada e materializada pelas práticas efetuadas a partir dele, por meio dele e para ele. Quais seriam essas construções de si mesmo evidenciadas em Shrek?

Há diferentes formas que não são estanques em Shrek. Ele permuta entre subjetividades diferenciadas na constituição de si mesmo. Shrek é capaz de ser um ogro terrível e pavoroso para grande número de aldeões. Mas ele é também capaz de buscar a

\footnotetext{
7 O filme "Shrek" (2001) é uma adaptação do conto literário Shrek, de William Steig, publicado em 1990, que alcançou grande sucesso (Steig, 2001). Outras informações sobre Steig podem ser lidas na dissertação de E. Silva (2007).
} 


\section{pro.posições}

satisfação de seus desejos sem o uso da força ou de atrocidades. Shrek pode ser absolutamente anormal, porque desajustado em relação às práticas sociais estabelecidas, desde a falta de cordialidade até os arrotos à mesa.

Essas irregularidades sociais, esses desajustes em relação às regras, vão adquirindo outras molduras, produzindo outros modos de ser em Shrek, quer seja, diferentes formas de subjetivação. É assim que sua anormalidade, seu desajuste e seu ser ogro assumem uma posição secundária em detrimento de outros elementos que o transformam num herói, mesmo com o rompimento de padrões.

Um herói atende sempre a um arquétipo, cuja existência tem como meta pessoal liberar, libertar, salvar alguém, salvar o outro (Bilotta, 2010). Shrek assim se caracteriza, ora como esse herói que salva, ora como anti-herói que não está nada interessado no outro ${ }^{8}$. Shrek cria e recria elementos subjetivos que se oferecem como modelos/exemplos a cada espectador que o recebe desse ou daquele modo.

Shrek pode abrir mão do romantismo, de certa sensibilidade, ou da etiqueta, mas também é visto a realizar gentilezas e a fazer agrados e doces declarações a Fiona. Ele pode se mostrar destemido, impetuoso, altivo e viril, mas também chora, sente medo, experimenta o sentimento de rejeição e de incapacidade. Shrek pode ser dono do próprio nariz ou pode ser flagrado recebendo ordens de Fiona. São modos de constituição de Shrek, maneiras pelas quais sua anormalidade se reconduz e assume outras molduras, mas são também formas e possibilidades de subjetivação oferecidas ao espectador por meio de sua personagem.

São multiplicidades constituidoras de Shrek, que ora é apresentado como anormal, ora como perfeitamente normalizado pelas regras sociais. Tais multiplicidades estão presentes ao longo dos quatro filmes analisados. Elas o subjetivam de um modo particular. Contudo, no apagar das luzes, ou acender delas, Shrek permanece muito mais como normalizado do que como aberrante.

Os processos de normalização foram considerados no sentido em que Shrek, apresentado como um ogro terrível, vai se tornando humanizado e tem, por diferentes

\footnotetext{
${ }^{8}$ Indo em outra direção, Shrek poderia ainda ser entendido como um herói moderno. Para Dumaresq (2007), um herói moderno é aquele que, ao descaracterizar certo protótipo, cumpre uma função mais questionadora que afirmativa. Também E. Silva (2007) considera Shrek como um herói moderno, porque consciente de si como anômalo, crítico e despido de falsa perfeição.
} 


\section{pro.posições}

mecanismos, a sua anormalidade amenizada. Tal anormalidade/normalidade é tomada do ponto de vista em que é construída historicamente e é sempre um efeito da aplicação de normas que qualificam, distribuem e hierarquizam as pessoas e/ou suas capacidades. Tal concepção de normalização tem apoio nos estudos de Foucault (1996), para quem a norma está sempre a balizar o que fica de um lado e o que fica de outro, segundo uma prática que classifica e separa os sujeitos. Foucault (1996) descreve operações que são postas em jogo nesses processos:

relacionar os atos, os desempenhos, os comportamentos singulares a um conjunto, que é ao mesmo tempo campo de comparação, espaço de diferenciação e princípio de uma regra a seguir. Diferenciar os indivíduos em relação uns aos outros e em função dessa regra de conjunto - que se deve fazer funcionar como base mínima, como média a respeitar ou como o ótimo de que se deve chegar perto ... em uma palavra, ela normaliza [ênfase no original]. (p. 163)

No vaivém dos momentos em que se coloca como normal e anormal (ora mais, ora menos normalizado socialmente), Shrek torna-se ainda mais próximo de muitos espectadores, traduzindo o desejo frequente daqueles que ambicionam permanecer na base do aceitável e ainda transgredir normas e padrões socialmente estipulados. Em outras palavras, traduzem o anseio humano de ser sempre considerado e/ou percebido como normal, ainda que transgredindo normas.

A Shrek é dada também a possibilidade de tornar-se humano, não ogro, por meio de uma poção mágica (Shrek 2, 2004). Ele adquire formas humanas e uma aparência considerada socialmente como aparente, máscula, bela e sexy - aparência essa que Shrek irá rejeitar. Sua feiura externa e aparente é transformada em beleza. Opõem-se feiura e beleza. Opõem-se ogro e humano. Ao mesmo tempo em que é um ogro (que rejeitou formas humanas), Shrek personaliza um ideal de homem. É assim que a série começa a caracterizar fortemente um modelo de humanidade, em que, se não será bela exteriormente, deixará de ser monstruosa para constituir-se normalizada. Uma ideia de humanização, que perscruta nuances para além daquelas características relacionadas à aparência, passa pelas situações e pelos dramas vividos por Shrek, que são próprios das relações humanas e rumam para o questionamento da forma de conceber o humano aludida na série. 


\section{pro.posições}

Importa, ainda, percebermos e destacarmos quais os mecanismos que são acionados no decorrer da transformação/constituição de Shrek. A amenização do horror de sua aparência é um deles. Em uma contemporaneidade que cultua a beleza, o corpo "sarado", malhado, esbelto, Shrek precisa sofrer, no interior dos filmes, uma transformação de sua imagem. Tais transformações atuam descaracterizando aos poucos a feiura de Shrek em um contínuo que tira de evidência sua aparência pavorosa e suas características monstruosas e anormais.

O convívio de Shrek com os outros - Fiona, amigos, família de Fiona - faz oposição ao ogro solitário do pântano, elemento que atua nos enredos evocados nos filmes para operar modificações significativas em Shrek.

Ele vivera sempre sozinho, nunca experimentara relacionamentos afetivos (família, amigos e namoradas) e desenvolvera dificuldades de convivência. Isso não o impediu de se relacionar com o Burro (no início, contra sua própria vontade) e, mais tarde, com o Gato de Botas, Fiona, Arthur, a rainha Líllian e até mesmo com o seu sogro, o rei Harold. A convivência com os outros faz Shrek mais humanizado, mais normal para o espectador. Esse é outro, dentre os mecanismos que identificamos, que atua nos processos de subjetivação de Shrek.

$\mathrm{Na}$ jornada de sua vida, nos relacionamentos que experimenta, Shrek aprende a expressar seus sentimentos. Os sentimentos dele são, a partir daí, um elemento em sua transformação. Por meio das experiências que Shrek vai elaborando na relação com os outros, os sentimentos experimentados por ele fazem um elo entre o sujeito personagem e o sujeito espectador.

Trouxemos aqui um excerto em que buscamos transcrever um diálogo do primeiro filme da série, em que Shrek se compara com cebolas?:

$9 \mathrm{O}$ excerto transcrito recupera de uma das animações analisadas um diálogo entre duas das personagens. Não são da mesma ordem que o audiovisual. Serão assim sempre incompletos, dada a limitação da transposição da linguagem audiovisual (extremamente complexa e múltipla) para a forma escrita. 


\section{pro·posições}

\section{Excerto de Shrek (2001):}

Os personagens de Sbrek e o Burro saem em busca de salvar a princesa Fiona e vão conversando pelo caminho. O Burro está inconformado com o modo como Shrek escolheu resolver as coisas].

Burro: Ok, deixa eu entender bem. Você vai lutar com um dragão e salvar uma princesa só pro Farquaad te devolver o pântano, que você só não tem, porque ele encheu de gente esquisita. É isso mesmo?

Shrek: Sabe, acho que tem um bom motivo pros burros não falarem.

Burro: Ah, eu não entendo Shrek. Por que você não deu uma de monstro neles? Sabe, estrangular, prender no castelo, moer os ossos e pôr no pão. Sabe? Serviço completo!?

Shrek: Ôhôh, Entendi. Talvez eu devesse ter decapitado toda a vila, pendurado as cabeças, pegado uma faca, cortado a barriga e bebido seus fluidos. O que é que você acha disso?

Burro: Ah... Não acho legal, não.

Shrek: Pra sua informação, há mais do que se imagina nos ogros.

Burro: Exemplo?

Shrek: Exemplo? Ok... Hã... Nós somos como cebolas!

Burro: Hum. Fedem?

Shrek: Sim. Não! [Como se o Burro tivesse entendido, mas logo repensando o que ele dissera].

Burro: Fazem você chorar?

\section{Shrek: Não!}

Burro: Oh, deixam eles no sol, eles ficam marrons e soltam aqueles cabelinhos?

Shrek: Não! Camadas! As cebolas têm camadas. Os ogros têm camadas. A cebola tem camadas. Entendeu? Nós dois temos camadas. Ahgh... [Shrek já está irritado com o Burro].

Burro: Ah... Vocês dois têm camadas, Ahh!... Sabe, nem todo mundo gosta de cebola... Bolo!! Todo mundo gosta de bolo e tem camadas.

Shrek: Eu não ligo!... pro que todo mundo gosta. Ogros não são como bolos!

Burro: Sabe uma coisa de que todo mundo gosta? Pavê!! Já conheceu alguma pessoa que você dissesse: vamos comer pavê e ela dissesse: "Céus, eu não gosto de pavê". 


\section{pro.posições}

Shrek: Não!!! Sua besta ambulante de irritação constante! Os ogros não são como a cebola. Fim da história. Bye, bye, tchauzinho. [Shrek desiste de explicar ao Burro a comparação que fer entre ogros e cebolas].

Shrek revela-se não ser apreciado como os bolos ou os pavês. Ele se sente como cebola, pouco degustada in natura. Para o Burro, ela fede e faz chorar, mas para Shrek é composta de camadas e não se resume apenas àquilo que é visível, aparente ou externo. Shrek está tentando dizer que ele não é apenas o ogro que se vê por fora. Está tentando mostrar seu interior, sua essência e, nesse dizer-se, constitui-se como bom (ainda que como personagem), como dotado de sentimentos. Ele usa a figura da cebola para ilustrar tal pluralidade em sua constituição. Evoca o sentido de uma humanidade que deve valorizar o que é interno e não o que é externo (aparente), ainda que não seja bem aceito por muitos (tal como a cebola).

Shrek experimenta, entre outros, o sentimento de rejeição. Shrek fala disso e, ao falar, constitui-se desse modo (ainda que como personagem fictícia e figura imaginária) e, com isso, constitui também a noção de rejeição de que fala. A explicitação desse sentimento o aproxima daqueles que individualmente ou histórica e culturalmente se sentem da mesma forma, evocando outros modelos de subjetivação e humanidade.

Shrek é capaz de sentimentos: de rejeição e inferioridade, de enamoramento, de ódio, de paixão, de amor, de arrependimento, de vergonha e de medo. Shrek é um ogro capaz até de chorar (como vemos em uma cena de Shrek para Sempre, 2010). Seus sentimentos fazem a ponte entre ele - o modo como se constitui - e o espectador. É um dos mecanismos bastante eficazes no processo que transforma o ogro em um Shrek humanizado.

A série Shrek é também organizada a partir de dramas humanos. A paixão não correspondida, a sensação de incapacidade, o desejo pela felicidade, a sensação de derrota ou de rejeição, a dificuldade em assumir responsabilidades, os conflitos que os filhos trazem ao casamento - entre outros que vão sendo explorados em todos os filmes - são experiências muito comuns nas relações humanas. Vivenciando tais dramas, ele é tornado ainda mais próximo das pessoas, cujas vidas são permeadas também por conflitos e 


\section{pro.posições}

vontades não permitidas. Sua presença nessas animações da DreamWorks além de ser uma estratégia de endereçamento a muitos espectadores (Ellsworth, 2001), também favorece essa sensação de que Shrek "é um de nós".

Cada drama, problema, conflito ou dificuldade vivida pela personagem aciona no espectador um pensar em direção a soluções possíveis para resolver as situações apresentadas (Guatari, 1980). Esse pensar, esse maquinar, desencadeia processos individuais de resolução de conflitos, e as escolhas feitas pelas personagens são uma entre as soluções possíveis para cada situação. Contudo o filme se oferece como possibilidade, como alternativa.

Shrek pode se entristecer, ficar atemorizado, ou mesmo chorar. Se com isso transgride uma postura esperada para os machos, isso também se soma a outras pequenas transgressões empreendidas por Shrek. Mas tal conduta não produz um olhar negativo sobre ele na série. Tais pequenas transgressões encontram algumas aprovações sociais, dentre elas, as críticas à supervalorização das formalidades e das etiquetas. Dessa forma, Shrek produz outra forma de endereçamento e ganha simpatias. Assim ele alcança ainda mais sujeitos.

Shrek se constitui como capaz de ser irreverente a certas normas, sem abrir mão de "ser ele mesmo" - e o mais importante -, sem por isso parecer mau, cruel, ou desumano; sem se recolocar como anormal. Ele é constituído como sendo bom na sua essência. Incapaz de crueldades. Esse mecanismo faz com que Shrek, em seus processos de subjetivação, seja percebido menos como ogro e mais como humano.

Há outro endereçamento operado por Shrek quando ele solta gases ou dá arrotos em situações em que isso não deveria acontecer. As expulsões fisiológicas (fezes, urina, gases e secreção dos ouvidos), que são a todos comuns, mas relegadas à intimidade, são tornadas transparentes, corriqueiras por Shrek. Ele se gaba e tem prazer nelas. Shrek expõe sua humanidade por agir assim e com certa irreverência.

Com isso, Shrek torna cada espectador um comparte seu. Tais comportamentos, aliados aos hábitos de alimentação e higiene realizados com "coisas nojentas", alcançam outros grupos de espectadores, porque são evidenciados como de absoluta naturalidade para Shrek. 


\section{pro·posições}

Essa personagem humanizada, esse Shrek humano, também é explicitado como tal pelos idealizadores-produtores, em diferentes momentos. Por exemplo, no trecho: "O essencial de Shrek é seu grande coração, que por fora age como um grande e aterrorizador ogro verde, mas você percebe que por dentro, há alguém com grande compaixão e um grande coração" (Holofote no Shrek, Shrek para Sempre, 2010).

Pelos processos de constituição da personagem, Shrek torna-se um de nós. Além de seus sentimentos, vivenciar os conflitos também o humaniza para o espectador. Shrek se constitui nessas dificuldades que experimenta. Suas atitudes e seus pensamentos produzem a experiência de si mesmo e operam as transformações de seu próprio eu. Em seus inúmeros endereçamentos ao espectador, vão sendo oferecidos modelos possíveis de resolução de problemas e constituição de si mesmo.

A forma como os idealizadores-produtores compõem a personagem faz de Shrek muito mais do que a pluralidade representada pelo ogro pavoroso por fora e o sujeito bom por dentro. Como uma cebola com muitas camadas, Shrek se constitui múltiplo e permuta entre essas muitas formas de ser.

Mas há um aspecto de Shrek que não é permeado pela sua habitual insubordinação às normas. O Shrek sexuado é exemplar, modelar, protótipo de uma sexualidade ajustada às normas sociais - e por que não dizer -, cristã conservadora.

Os quatro filmes da série Shrek não tematizam a sexualidade, visto que ela não é colocada em evidência pelas animações. Nem por isso está implícita nos filmes. Ela é explicitada sob os pontos de vista dos relacionamentos heterossexuais, dos comportamentos esperados dos enamorados, dos "casados", incluindo o imperativo da reprodução e a formação da família como consequência direta (e adequada) à união. ${ }^{10}$

\footnotetext{
${ }^{10}$ Isso não quer dizer que só há na série o modelo heterossexual representado por Shrek. Há personagens caracterizadas de modo diferenciado. As imagens de duas dessas personagens sugerem serem homens travestidos de mulheres, caracterizadas com traços masculinos e voz grave. Noutros momentos, a trama revela a possibilidade de que elas sejam irmãs de Cinderela (Drizela e Anastácia), já que o rei Harold chama uma delas, Doris, de irmã feia. Ela seria talvez atendente, talvez dona do Bar Maçã Envenenada, lugar onde os vilões se encontram. Noutro momento, Príncipe Encantado se dirige a outra delas como Mabel e revela ser ela a irmã de Cinderela. Ele pergunta a Mabel sobre Doris, sugerindo novamente que sejam irmãs. Há ainda uma cena em que Pinóquio é flagrado usando roupa íntima feminina, fato que ele nega e que é repetidamente reafirmado por outras personagens para que Pinóquio continue negando, fazendo seu nariz crescer, o que as leva a obter sucesso em uma situação de fuga. A figura do lobo mau, do dragão fêmea, do amor entre sapo e princesa, entre burro e dragão fêmea são outros exemplos que poderiam ser pensados nessas direções.
} 


\section{pro.posições}

Louro (2000) assegura ser o cinema uma das formas culturais mais significativas de nossa sociedade, de notável popularidade e alcance. Entende que o cinema atua como uma pedagogia cultural que engendra práticas sociais e identidades culturais na sociedade brasileira. Para ela, o cinema produz e difunde representações padronizadas e identidades dominantes de homens e mulheres heterossexuais. Nas palavras da autora, ele participa “ de um processo pedagógico mais amplo" (p.426).

É possível visualizar isso na série. Shrek forma sua família, casando-se com Fiona e consolida-a por meio dos filhos. Shrek namora Fiona de modo arquétipo, sem extravasar qualquer impulso ou desejo sexual. Ele se casa religiosamente com Fiona (nos dois sentidos do termo): troca alianças na igreja, retira-se para uma lua de mel a dois (com direito a filmagens dos momentos especiais), cumprindo até mesmo o ritual de pegar a esposa nos braços, enquanto adentra o local onde será consumado o ato sexual.

Shrek torna-se pai a tempo certo: depois do casamento com Fiona, depois de conhecer o seu sogro e sogra, depois de reconquistar as terras de seu pântano (indicando a necessidade de posses para a constituição da família). Até mesmo as brigas entre Shrek e Fiona reproduzem os desentendimentos considerados "normais" ou costumeiramente esperados para um casal.

As práticas de Shrek de uso da sexualidade o constituem esse ser conformado às normas sociais vigentes. No uso da sexualidade, portanto, é que Shrek se constitui o mais normalizado possível, e nesse ínterim reforça certo modo ideal de humanização.

Analisar os processos de subjetivação é fundamentalmente investigar os procedimentos de constituição de si, as práticas de si mesmo, a relação de si para si. É necessariamente um mover-se no campo ético.

estudar a constituição do sujeito como objeto para ele próprio: a formação dos procedimentos pelos quais o sujeito é levado a se observar, se analisar, se decifrar e se reconhecer como campo de saber possível. Trata-se, em suma, da história da "subjetividade" [ênfase no original], se entendermos essa palavra como a maneira pela qual o sujeito faz a experiência de si mesmo em um jogo de verdade, no qual ele se relaciona consigo mesmo. (Foucault, 2004, p. 236) 


\section{pro.posições}

Subjetivação e sexualidade tomam dimensões intercambiáveis. Pode-se dizer, com Foucault (1988), que a sexualidade se inscreve no campo das práticas que o sujeito opera sobre si mesmo, produzindo-se, transformando-se, subjetivando-se:

a ênfase é dada, então, às formas das relações consigo, aos procedimentos e às técnicas pelas quais são elaboradas, aos exercícios pelos quais o próprio sujeito se dá como objeto a conhecer, e às práticas que permitem transformar seu próprio modo de ser. (p. 30)

Com esse entendimento de sexualidade (que, nos últimos estudos de Foucault, foi por ele associada às técnicas de existência, às práticas de si como modos de subjetivação do sujeito), procuramos compreender os processos vividos pela personagem Shrek, inscritos nas práticas que permitem ao sujeito diferentes experiências de si mesmo, diferentes modos de subjetivação.

O último drama vivido por Shrek leva-o a acreditar que a tal vida de casado não era a vida de um "ogro de verdade", mas sinônimo de infelicidade. Contudo, ao lhe serem retirados tal condição e o modo de existir no mundo, Shrek vai ao "fundo do poço", porque perdera a sua família. "Minha família era perfeita" (Shrek para Sempre, 2010), lastima ele. Este foi seu lamento, ao se descobrir infeliz por tal perda.

Para reaver a sua família, seu amor verdadeiro, seu relacionamento com Fiona, sua felicidade - e também podemos dizer: para reaver o modo de exercício de sua sexualidade -, Shrek empregará todas as suas forças.

Reconquistar tal condição de vida para si mesmo é consequência da reconquista do amor de Fiona (o amor verdadeiro) e da família. É o modo que Shrek vê disponível para cuidar de si mesmo. É a única opção para seu modo de existir - ou de continuar existindo. Shrek existe por meio da existência de sua família e de seu amor. Acreditamos residir aí a mais forte alegoria para essa humanização da personagem e que vai se dando no interior de um processo de normalização. Tudo isso é oferecido ao espectador como modelo à sua própria relação consigo mesmo. 


\section{pro.posições}

Salvando a família, Shrek salva a si mesmo e se torna herói na série. Esse é o modelo disponibilizado como exemplo, ideal, para o cuidado de si mesmo. Essa é a alternativa apresentada como desejável para se continuar existindo: por meio de uma sexualidade obediente a tais normas sociais, que normalizam o sujeito e suas práticas de si mesmo e de relação com o outro.

Shrek é mais ou menos subjetivado por uma série de processos de normalização. $\mathrm{Na}$ maioria deles, o que se produz são efeitos que amenizam sua condição (a princípio apresentada como anormal), produzindo-o como um ogro normal e humanizado. Contudo, diante das normas sociais que estipulam as regras para o uso da sexualidade, Shrek se constitui o mais ajustado e conservador possível e, pela defesa delas, é tornado herói.

Em seus processos de subjetivação - que trazem em seu bojo um processo paralelo de humanização e também de reforçamento de certo ideal de humanidade - vemos duas técnicas aparecendo em diferentes momentos, participando desse projeto empreendido pelos produtores-idealizadores na fabricação de tal Shrek. São as técnicas de confissão e de exame. Diversos são os momentos em que Shrek é levado a falar de si mesmo, a confessar-se, a expressar oralmente seus sentimentos, suas alegrias e suas decepções. Ele mesmo é que se define por meio do que fala no primeiro filme da série. A essa técnica, Foucault (2001) deu especial atenção, compreendendo-a como uma das tecnologias discursivas de constituição do sujeito.

A outra técnica é a técnica do exame. A personagem de Shrek também exemplifica essa maneira de operar sobre si. Quando pensa sobre como vai agir, reflete sobre a adequação de suas ações, reexamina e arrepende-se de certas atitudes e decide reflexivamente sobre o que é ou não importante para ele. Assim se constitui outro.

Essas duas técnicas, da confissão e do exame são abordadas por Foucault (1996, 2001) como constitutivas da engrenagem que nos produziu/produz como sujeitos.

Em Shrek para Sempre (2010), Shrek é o salvador e herói, que abdica de si mesmo, que reconhece a felicidade na família, na reconquista do amor verdadeiro. Mas é também o salvo, que somente volta a existir porque, tendo reconquistado seu amor verdadeiro, é digno de receber o beijo que lhe devolve a existência. O beijo representa o amor verdadeiro entre eles. Aliás, o beijo é uma das características de expressão do amor verdadeiro na série. 


\section{pro.posições}

O amor verdadeiro é caracterizado como existindo genuinamente heterossexual, tendo sua face sexual apenas após o casamento, ato que também leva à procriação.

O beijo de Fiona e Shrek sela e imprime determinadas características como constituidoras do amor verdadeiro. Foi o beijo de amor verdadeiro que desfez o feitiço de Fiona (Shrek, 2001), que manteve Shrek e Fiona em suas formas de ogro (Shrek 2, 2004), e que anulou o infeliz acordo de Shrek com Rumpelstiltskin, trazendo-lhe de volta sua vida, sua família e sua felicidade (Shrek para Sempre, 2010). Ele (o beijo) também sela um modo considerado adequado socialmente (conforme a norma) de uso da sexualidade. Ele se liga ao casamento e à constituição da família.

Assim é reforçado também um modelo de humanidade, cuja felicidade e contentamento plenos estão contidos no outro. Somente encontrando e conquistando o amor verdadeiro (no outro) se obtém a felicidade plena. Perder o amor verdadeiro é perder a felicidade, é perder-se a si mesmo. Preservar o amor verdadeiro e, nele, a família e os filhos, é manter-se existindo, é cuidar de si mesmo.

Assim culmina o modelo de humanidade que perpassa toda a série. Uma humanidade que deve ser zelosa do outro, abdicável de si mesmo em favor do outro, especialmente quando o que está em jogo é o amor verdadeiro e a felicidade. De fato, há mais do que o está aparente à primeira vista na personagem de Shrek. Cheio de camadas, ele se revela, contudo, apreciado e estimado por muitos, em contraposição à sua analogia com as cebolas.

Os filmes de Shrek funcionam como pedagógicos na medida em que medeiam os processos de constituição de si, ao oferecer certos modelos de uso da sexualidade, certas ideias de humanização e de oscilações entre desajuste e conformação às normas. Eles são oferecidos como possibilidades ao espectador e aos processos de experiência de si mesmo.

Não estamos a dizer que o ato de assistir aos filmes de Shrek se constitui na ação determinante que define a vida do espectador em conformidade com este ou aquele modelo de obediência a normas, regras e padrões sociais. Os filmes são um entre os elementos pedagógicos que medeiam essa relação. Eles são um entre uma diversidade de formas cultural e historicamente possíveis, capazes de afetar os modos pelos quais os sujeitos se constituem e são subjetivados. 


\section{pro.posições}

Nem por isso deixam de ser importantes. O cinema é partícipe da invenção do sujeito moderno (Charney \& Schwartz, 2004). Como mencionamos, os filmes acionam em cada espectador um maquinar, um pensar, um refletir a respeito dos dramas/problemas e das dificuldades abordados (Guatari, 1980). Eles se tornam importantes desencadeadores de decisões e ideias individuais.

Do mesmo modo a experiência do espectador de assistir aos filmes de Shrek se constitui em uma possibilidade de que os modos de subjetivação ali superpostos e permutados sejam também partícipes da constituição de sua subjetividade.

Quantos de nós não desejamos agir tal como Shrek (em alguma de suas multiplicidades), ao assistir aos filmes da série?

Ainda que não seja Shrek mesmo que se subjetiva, mas entendendo que tudo o que ali se passa são deliberações de seus produtores-idealizadores, ainda assim temos de pensar em como é dado a personagem, agir sobre si, refletir sobre si, cuidar de si e transformar-se. Ou como ele é apresentado nos seus processos de subjetivação. Objetivamos analisar o processo mesmo apresentado nos filmes, na medida em que vai compondo e oferecendo ao espectador mecanismos e formas múltiplas de subjetivação.

Por meio da reflexão sobre o processo fictício de subjetivação de Shrek, podemos vislumbrar a nós mesmos, constituindo-nos a partir de nossas experiências pelos modos como nos relacionamos conosco e com os outros, relações sempre permeadas pelas limitações assentadas entre o permitido e o proibido, entre o aceitável e o indesejável, entre o que é normal e regular e o é que tido como anormal e inconcebível.

Se nos detivermos sobre nós mesmos, podemos ver o quanto recorremos, individual e historicamente, às mesmas técnicas utilizadas nos filmes, em nossos processos de subjetivação. Somos mais ou menos capturados por meio delas tal como Shrek.

As relações que estabelecemos com as pessoas que nos cercam, as normas a que nos conformamos ou as que desconsideramos, o que falamos de nós mesmos, os usos que fazemos de nossa sexualidade e o que temos como imperativo ao decidirmos sobre nossas atitudes, o que nos afeta (ou nem faz diferença) e nos atinge emocionalmente, provocando riso ou choro, o pensar que exercemos sobre nós mesmos, e as transformações que 


\section{pro·posições}

10.1590/1980-6248-2015-0173

operamos (ou que recusamos operar) sobre nós mesmos, o modo como cuidamos de nós e do outro e o que valorizamos, ou não, nesse processo, são todos modos pelos quais somos também capturados. São maneiras pelas quais nos subjetivamos de um modo múltiplo não linear, tal como Shrek em seus processos de subjetivação. Assim, pensando sobre Shrek, quisemos contribuir com um pensar sobre como nos tornamos o que somos.

\section{Referências Bibliográficas}

Bilotta, F. A. (2010). Heroinas - da submissão à ação: uma análise junguiana de personagens em filme de animação. Dissertação de Mestrado em Psicologia Clínica, Pontifícia Universidade Católica de São Paulo, São Paulo, Brasil.

Charney, L., \& Schwartz, V. R. (2004). O cinema e a invenção da vida moderna (2a ed., ed. rev., R. Tompson, trad., Coleção Cinema, Teatro e Modernidade) São Paulo: Cosac\&Naify.

Corrêa, A. (2006). O ogro que virou principe: uma análise dos intertextos presentes em Shrek. Dissertação de Mestrado em Letras, Pontifícia Universidade Católica do Rio Grande do Sul, Porto Alegre, RS, Brasil.

Costa, M. V. (2002, maio/agosto). Ensinando a dividir o mundo; as perversas lições de um programa de televisão. Revista Brasileira de Educaşão, 20, 71-82.

Denis, S. (2010). O cinema de animação (M. Félix, trad., Coleção MI·MÉ·SIS Artes e Espetáculo). Lisboa, Portugal: Edições Texto \& Grafia.

Duarte, R. (2006). Cinema \& educação (2a. ed.). Belo Horizonte: Autêntica. 


\section{pro.posições}

10.1590/1980-6248-2015-0173

Duarte, R., \& Alegria, J. (2008). Formação estética audiovisual: um outro olhar para o cinema a partir da educação. Revista Educação \& Realidade. Dossiê. Cinema e Educação, 33(1), 59-79.

Dumaresq, D. D. (2007). Sobre heróis, narradores e realismo: análise de filmes de Jean Rouch. Tese de Doutorado em Sociologia, Universidade de São Paulo, São Paulo, SP, Brasil.

Ellsworth, E. (2001). Modos de endereçamento: uma coisa de cinema, uma coisa de educação também. In T. T. Silva (Org.), Nunca fomos bumanos: nos rastros do sujeito (pp.7-76) Belo Horizonte, MG: Autêntica.

Fischer, R. M. B. (2007). Mídia, máquinas de imagens e práticas pedagógicas. Revista Brasileira de Educaşão, 12 (35), 290-299.

Foucault, M. (1988). História da sexualidade II: o uso dos prazeres (5a. ed., M. T. C Albuquerque, trad.) Rio de Janeiro: Graal.

Foucault, M. (1996). Vigiar e punir: nascimento da prisão (13a. ed., R. Ramalhete, trad.) Petrópolis: Vozes.

Foucault, M. (2001). História da sexualidade I: a vontade de saber. (14a. ed., M. T. C Albuquerque, \& G. Albuquerque, trads.). Rio de Janeiro: Graal.

Foucault, M. (2004). Ética, sexualidade, politica/Michel Foucault (M. B. da Motta, org. e seleção de textos, E. Monteiro, \& I. A. Dourado, trads., Coleção Ditos e Escritos, vol. V).Rio de Janeiro: Forense Universitária.

Giroux, H. A. (2004). A disneyzação da cultura infantil. In T. T. Silva, \& A. F. Moreira (Orgs.), Territórios contestados: o currículo e os novos mapas politicos e culturais (6a. ed., pp.49-81). Petrópolis, RJ: Vozes.

Gomes, P. E. S. (2011). A personagem cinematográfica. In A. Candido, Antonio et al., A personagem de fiç̧ão (12a. ed., pp. 104-119, Coleção Debates). São Paulo: Perspectiva.

Guattari, F. (1980). O divã do pobre. In C. Metz, J. Kristeva, F. Guattari, \& R. Barthes, Psicanálise e Cinema (pp. 105-117, P. A. Ruprecht, trad.). São Paulo: Global. 


\section{pro.posições}

Louro, G. L. (2000). O cinema como pedagogia. In Lopes, Mendes, \& Greive (Orgs.), 500 anos de educaşão no Brasil (pp. 423-446). Belo Horizonte: Autêntica.

Machado, L. M. M. (2006). E a midia criou a mulher: como a tv e o cinema constroem o sistema de sexo/gênero. Tese de Doutorado em História, Universidade de Brasília, Brasília, Brasil.

Mayrink, M. F. (2007). Luzes... câmera... reflexão: formação inicial de professores mediada por filmes. Tese de Doutorado em Linguística Aplicada e Estudos da Linguagem, Pontifícia Universidade Católica de São Paulo, São Paulo, Brasil.

Momo, M. (2009). A tecnologização dos desejos. In M. V. Costa, (Org.), A educação na cultura da midia e do consumo (pp. 203-205). Rio de Janeiro: Lamparina.

Santos, M. R. dos. (2009). O "diferente" e o "feminino" em Shrek: uma análise das formações discursivas. Dissertação de Mestrado em Estudo de Linguagens, Universidade do Estado da Bahia, Salvador, BA, Brasil.

Silva, E. M. da. (2007). Shrek, do conto ao filme: um "reino" não tão distante. Dissertação de Mestrado em Letras, Universidade Federal da Paraíba, João Pessoa, PB, Brasil.

Silva, R. P. (2007). Cinema e educação. São Paulo: Cortez.

Steig, W. (2001). Shrek: a história que inspirou o filme (E. Brandão, trad.). São Paulo: Companhia das Letrinhas.

Vieira, T. C. (2008). O potencial educacional do cinema de animação: três experiências na sala de aula. Dissertação de Mestrado em Educação, Pontifícia Universidade Católica de Campinas, Campinas, SP, Brasil.

\section{Filmografia (filmes analisados):}

Adamson, A., \& Jenson, V. (Direção), Warner, A., Williams, J., \& Katzenberg, J. (Produção). (2001). Shrek (DVD/vídeo - 1 filme; 93 min. Cor. Livre. Família. [Tema: Amizade]). EUA: DREAMWORKS ANIMATION SKG. 


\section{pro.posições}

10.1590/1980-6248-2015-0173

Adamson, A., Asbury, K., \& Vernon, C. (Direção), Warner, A., Lipman, D., \& Williams, J. (Produção). (2004) Shrek 2 (DVD/vídeo - 1 filme; 93 min. Cor. Livre. Família. [Tema: Amizade]). EUA: DREAMWORKS ANIMATION SKG.

Miller, C. (Direção), Warner, A. (Produção). (2007). Shrek terceiro (Shrek the Third / Shrek 3) (DVD/vídeo - 1 filme; 93 min. Cor. Livre. Família. [Tema: Invasão do Reino Encantado]). EUA: DREAMWORKS ANIMATION SKG.

Mitchell, M. (Direção), Shay, G., \& Cheng, T. (Produção). (2010). Shrek para sempre (Shrek Forever After) (DVD/video - 1 filme; 93 min. Cor. Livre. Família. (Tema: Amizade). EUA: DREAMWORKS ANIMATION SKG.

Submetido à avaliação em 17 de dezembro de 2015; aprovado para publicação em 21 de julho de 2016. 